nium injections, however, she said discussions regarding compensation would begin immediately with their families. "One thing all of us want to avoid is a protracted and expensive lawsuit against the government." Such studies were undertaken in secret during World War II to help assess radiation risks to workers involved in the development of the Atomic Bomb. This was long before it became standard practice to obtain the 'informed consent' of medical research subjects by first laying out the risks and benefits of participation. The experiments ended during a watershed year, 1974, when the govemment recognized the need to protect human subjects, and issued regulations governing the conduct of such research.

The panel also recommended that Congress consider amending an existing law, the Radiation Exposure Compensation

\section{Teen marijuana use in US doubles in three years}

Marijuana smoking among teenagers in the United States has nearly doubled since 1992, a surprising reversal due in part to an increasing perception among youngsters that the drug is harmless.

Monthly marijuana use among 12- to 17-year-olds rose to 7.3 percent - or 1.3 million teens - in 1994, up from 4.0 percent in 1992 and 4.9 percent in 1993 . according to the Household Survey on Drug Abuse, conducted by the Substance Abuse and Mental Health Services Administration. In 1979, when the use of all illicit drugs was soaring in the United States, 16.8 percent of that age group smoked marijuana.

The survey, based on a nationally representative sample of 22,181 people age 12 and older, is the primary source of statistical information on the use of illegal drugs in the United States. For the purposes of the study, drug use was defined as having used the drug sometime in the month before the survey was conducted.

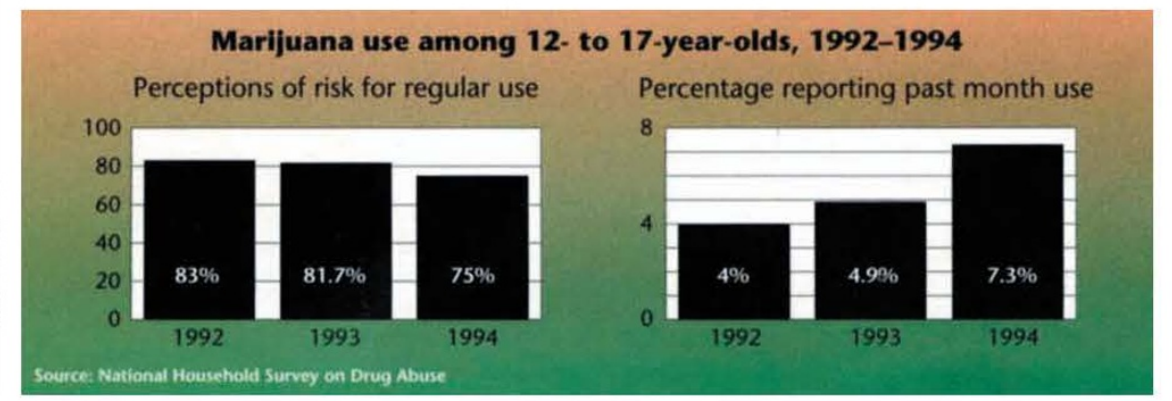
Act of 1990, to provide compensation to all uranium miners who develop lung cancer after a minimal period of time working underground, regardless of the specific level of uranium exposure.

Clinton has now ordered a review of the procedures involving all government-sponsored research on humans, and will create a bioethics advisory commission (see page right) to undertake the task and those of a similar 'sensitive' nature. Bioethicist Arthur Caplan of the University of Pennsylvania, called Clinton's public apology an act of "great moral significance." He added, "I know it's a symbolic gesture, but one very well worth making."

Marlene Cimons Washington, $D C$

\section{DID YOU KNOW?}

Plans firm up for US national bioethics panel Plans for a US National Biomedical Ethics Advisory Committee were formally announced at the beginning of last month. As expected, the panel's initial focus will centre on issues relating to the welfare of humans participating in research studies and questions of how to handle genetic information (Nature Medicine 1, 287; 1995).

The new panel is sanctioned for two years, after which it will disband, unless the administration at the time extends its lifetime.

The panel's first specific task is related to the work of the Advisory Committee on Human Radiation Experiments. During the next four months, all government agencies undertaking research involving humans must review their regulations in light of the radiation panel's recently published findings (see pages 1112-1113). Their reports, including plans for making any improvements necessary in their guidelines, are to be submitted to the bioethics panel.

The panel's role is to give advice to the National Science and Technology Council. It can propose subjects for further review but needs the Council's approval before undertaking the study.

Helen Gavaghan Washington, $D C$ who was secretary of health, education and welfare under former President Jimmy Carter and who now heads the Center on Addiction and Substance Abuse at Columbia University in New York.

The survey also found that the total number of illicit drug users has remained constant since 1992, and that casual cocaine use has continued to drop. Experts warned, however, that the change in marijuana use could foreshadow a surge in cocaine use, as research indicates that those who smoke marijuana are many times more likely later to use cocaine.

MARLENE CIMONS Washington, $D C$

\section{Research shows AZT and either} ddl or ddC better than AZT alone Britain's Medical Research Council is recommending that people with HIV infection and AIDS take a combination of two anti-AIDS drugs, following the recently released results of the Delta trial involving 3,000 individuals in Europe and Australia. The trial was stopped three months early when it was shown that a combination of AZT, with either ddl (didanosine, BristolMyers Squibb), or ddC (zalcitabine, Roche), led to an average 38 percent reduction in death rates, compared to taking AZT - now often the first line of defence - alone.

Preliminary results of the largest clinical trial comparing single and combination treatments were presented by Brian Gazzard of the Chelsea \& Westminster Hospital, London, at the Fifth European Conference on Clinical Aspects and Treatment of HIV Infection in Copenhagen, Denmark, at the end of September.

Nuala Moran London 